\title{
Simulation of mitigation strategies to reduce nitrogen leaching from grazed pasture
}

\author{
J.R. BRYANT, C.J. HOOGENDOORN and V.O. SNOW \\ AgResearch Limited, Grasslands Research Centre, Tennent Drive, Private Bag 11008, \\ Palmerston North 4442, New Zealand. \\ Jeremy.Bryant@agresearch.co.nz
}

\begin{abstract}
Strategies to reduce nitrogen leaching losses from pastoral farming in the Lake Taupo catchment are required to address declining water quality in the lake. This study used a biophysical whole farm simulation model, EcoMod, to explore the potential for four mitigation strategies to reduce $\mathrm{N}$ leaching in a soil and climate typical of the region. The strategies were use of: a nitrification inhibitor (DCD); steers instead of heifers (STEER); salt as a diuretic (SALT) and; high sugar ryegrass (HSG). These were compared to a BASE scenario of grazed heifers. Each of the simulated mitigation strategies showed the potential to significantly reduce nitrogen leaching compared to BASE by 25 to $45 \%$. All mitigation strategies reduced nitrogen fixation due to more efficient plant use of nitrogen from urinary and faecal sources. This also contributed to an increase in pasture intake for SALT, STEER and DCD, but not for HSG. These mitigation strategies were explored at a single-paddock level and planned experimental studies will further examine the effectiveness of the strategies.
\end{abstract}

Keywords: nitrogen leaching, mitigation, Lake Taupo, simulation, EcoMod

\section{Introduction}

Over the last 50 years, more intensive land use by grazing animals around Lake Taupo has increased the amount of nitrogen (N) entering the lake (Anonymous 2006). This has had a negative effect on Lake Taupo with mean annual algal abundance increasing and water clarity declining (Edgar 1999) and significant increases in nitrate-N in Lake Taupo since 1976 (Gibbs 2006). In grazing systems, the major source of $\mathrm{N}$ available for leaching is urine which is deposited at very high localised rates, up to $1000 \mathrm{~kg} \mathrm{~N} / \mathrm{ha}$ (Wachendorf et al. 2005). This concentration far exceeds plant requirements for growth, and consequently the excess $\mathrm{N}$ is prone to leaching as nitrate or ammonium (Haynes \& Williams 1993).

Potential regulatory limits on $\mathrm{N}$ leaching in the Taupo area make the identification of effective $\mathrm{N}$ leaching mitigation strategies particularly important. Several mitigation strategies have been proposed including the application of dicyandiamide (Di \& Cameron 2002, 2004a; Smith et al. 2005), the use of ryegrasses with high concentrations of water soluble carbohydrates (i.e. high sugars) to increase $\mathrm{N}$ use efficiency (Merry et al. 2006), the addition of diuretics to the diet and the use of steers as opposed to heifers (Ledgard et al. 2007).

Nitrogen leaching losses depend on multiple factors such as soil type, which affects nutrient and water holding capacity, climate, topography, type of pasture, farm management and stocking density, the type of animals grazing the land and the duration of the grazing period. In addition, many mitigation strategies can take many years, beyond the normal scope of experimental studies, to have their full effect on the agro-ecosystem. Computer simulation is an effective way of integrating many of these components to predict the long-term effectiveness of mitigation strategies. The objective of this study was to use a biophysical simulation model, EcoMod, to predict the expected levels of $\mathrm{N}$ leaching, $\mathrm{N}$ fixation and pasture intake with different mitigation strategies compared to a base simulation.

\section{Materials and Methods}

EcoMod version 4.0.6 was used for all simulations. EcoMod is a biophysical pastoral simulation model developed for New Zealand and Australian grazing systems (Johnson et al. 2008). The model includes modules for pasture growth and utilisation by grazing animals, animal physiology including production, water and nutrient dynamics, and a range of options for pasture management, irrigation and fertiliser application.

\section{Weather}

A Taupo weather file consisting of daily rainfall, maximum and minimum temperatures, mean humidity, and solar radiation for the period of 1972 to 2005 was collated from various meteorological stations in the Taupo area. These data were used to stochastically create a 100 year weather file using the modified version (Verburg et al. 2005) of the daily climate model from the Stochastic Climate Library (SCL) (Srikanthan \& Zhou 2003). In the SCL, daily climate data are generated using a first order autoregressive multivariate model created by analysing actual weather data and the relationships that exist between days within months. Overall, the temporal patterns and range of maximum and minimum temperature, solar radiation, rainfall and mean relative humidity were very similar in the actual and simulated 
data (data not shown). Mean relative humidity was slightly lower in the simulated than actual data.

\section{Soil properties}

The soil properties used in these simulations were for Oruanui Sand which is described as a strongly-leached Podzolic Orthic Pumice Soil. Most of the soil properties were obtained from the National Soils Database (Wilde 2003 ) using the soil identity number "SB08847". The soil is typical of the region and has a high hydraulic conductivity, a relatively low storage of plant-available water, and a low cation exchange capacity. Data from two experimental studies (M. Sprosen and C Hoogendoorn, AgResearch - unpublished data) where urine was applied to a Taupo soil were used to calibrate soil properties in EcoMod to ensure that the nitrogen leaching predicted was in line with measured values.

\section{Model set up}

EcoMod was set up as a "single heterogeneous paddock". In this option, EcoMod simulates a single paddock with many patches. At each grazing, the stock arrive on the paddock and graze the patches, which can have strongly differing standing dry matter. However, the excreta are returned only to some patches. For example if urine was returned to two patches (as in the BASE simulation below) then patches 1 and 2 received urine at the first grazing, patches 3 and 4 at the second grazing, and so on. In this sequence, urine would be deposited on $2.5 \%$ of the paddock area at each grazing and any patch would receive urine every 40th grazing. Urine patch overlap was not considered in this set up.

\section{BASE simulation}

The BASE simulation was set up to represent grazing heifers. The single heterogeneous paddock was set up with 80 patches, each representing $1.25 \%$ of the paddock area. At each grazing, nutrients were returned to two patches or $2.5 \%$ of the grazing area, with patches rotated in sequence. The value of $2.5 \%$ of the paddock area receiving excreta, while a simplification, was based on the assumption of an average stocking density of 100 animals/ha, $0.25 \mathrm{~m}^{2}$ covered per urination and 10 urinations/animal/day (Haynes \& Williams 1993). It was assumed that there were sufficient animals available to graze the pasture whenever they were required to prevent excessive senescence. The model considers that animals eating feed with higher concentrations of crude protein, and/or consuming feed with lower concentrations of energy, excrete more $\mathrm{N}$ in urine and less in dung. The paddock was grazed whenever average pasture mass was $2200 \mathrm{~kg} \mathrm{DM} / \mathrm{ha}$ and was grazed down to $1400 \mathrm{~kg}$ $\mathrm{DM} / \mathrm{ha}$. Nutrient removal in liveweight gain was set at $15 \%$ of total $\mathrm{N}$ intake, with previous studies in heifers reporting anything from 12 to $29 \%$ of $\mathrm{N}$ retained as liveweight gain (Davenport et al. 1990; Marini \& Van Amburgh 2005). No fertiliser $\mathrm{N}$ was applied.

\section{Mitigation strategies}

1. Use of dicyandiamide (DCD)

The proposed mitigation strategy using DCD is to apply it as a drench in the autumn and winter period (Ledgard et al. 2007). EcoMod currently does not have the capability to model DCD in this way. Therefore, this mitigation strategy was modelled by applying DCD four times (1 February, 1 April, 1 June, and 1 August) each year. The effect of each DCD application was assumed to last for 100 days based on a Southland study by Smith et al. (2005). It was assumed that DCD reduced nitrification rates over the whole paddock by a maximum of approximately $90 \%$ on day 1 of application, $50 \%$ at day 60 and $0 \%$ at day 100 based on the results of Di and Cameron (2004b) at soil temperatures of $8^{\circ} \mathrm{C}$.

\section{Use of steers instead of heifers (STEER)}

Observations of urine deposition suggest that, due to anatomical differences, urine is spread over a greater area by steers than by heifers. Consequently, the area at each grazing covered in urine was increased to cover $3.75 \%$ of the paddock area. In addition, steers grow faster than heifers with more $\mathrm{N}$ retained in liveweight gain. Based on the equations presented in SCA (1990), it was calculated that a $0.3 \mathrm{~kg} /$ day increase in liveweight would result in approximately a $3 \%$ increase in $\mathrm{N}$ use efficiency. Consequently, the amount of $\mathrm{N}$ retained in liveweight gain was lifted from 15 to $18 \%$ in the STEER mitigation strategy.

\section{Adding salt to the diet (SALT)}

Previous trials with dairy cows indicate the number of urinations on a salt-added diet is double that on a diet without salt, diluting the $\mathrm{N}$ concentration of urine of animals on the former diet (Ledgard et al. 2007). To incorporate the effect of the diuretic, the area covered in urine at each grazing in EcoMod was increased to 5\% of the paddock area, which acted to reduce the concentration of $\mathrm{N}$ in the urine-affected soil.

\section{Use of high sugar ryegrasses (HSG)}

The consumption of high sugar ryegrasses (HSG) by cattle provide rumen microbes with a greater energy source for the synthesis of microbial protein than traditional ryegrass varieties (Merry et al. 2006), thereby increasing the efficiency of $\mathrm{N}$ use by grazing cattle. To simulate the effect of $\mathrm{HSG}$, the amount of $\mathrm{N}$ retained in liveweight gain was lifted from 15 to $20 \%$. A $5 \%$ increase in the amount of $\mathrm{N}$ excreted as faeces ( $5 \%$ reduction in the amount of $\mathrm{N}$ excreted as urine), was assumed based 
on a study by Moorby et al. (2006) in lactating dairy cattle. In addition, a 3\% increase in pasture digestibility was simulated based on the findings of Moorby et al. (2006).

\section{Data analysis}

Each of the scenarios, BASE, DCD, STEER, SALT and HSG was simulated in EcoMod using the same soil and 100 -yr weather file in order to obtain median, mean, minimum, maximum and 0.25 and 0.75 quartiles for annual $\mathrm{N}$ leaching, $\mathrm{N}$ fixation and pasture intake for each scenario. The sign test of the UNIVARIATE procedure of SAS was used to test the hypothesis that the median of the annual differences in the pairs (BASE compared to DCD, STEER, SALT and HSG) was zero for total N leaching, $\mathrm{N}$ fixation and pasture intake. The sign test was appropriate as data were non-normal and skewed.

\section{Results and Discussion}

\section{BASE scenario}

Minimal pasture growth occurs from May to July with peak growth occurring in November and December (Fig. 1). Pasture growth rates for the BASE scenario were similar to total and seasonal estimates obtained by Baars et al. (1975) for a hill country pasture at Wairakei, north of Taupo. Simulated nitrogen leaching exhibited a peak in July and August for the BASE simulation with another peak also occurring in February (Fig. 2), coinciding with

Figure 1 Cutting trial estimates (-o- \pm standard errors) based on Baars et al. (1975) and $25^{\text {th }}$ to $75^{\text {th }}$ percentile of daily pasture growth rates $(\square$ ) of the BASE simulation over a 100 year simulation period for each month.

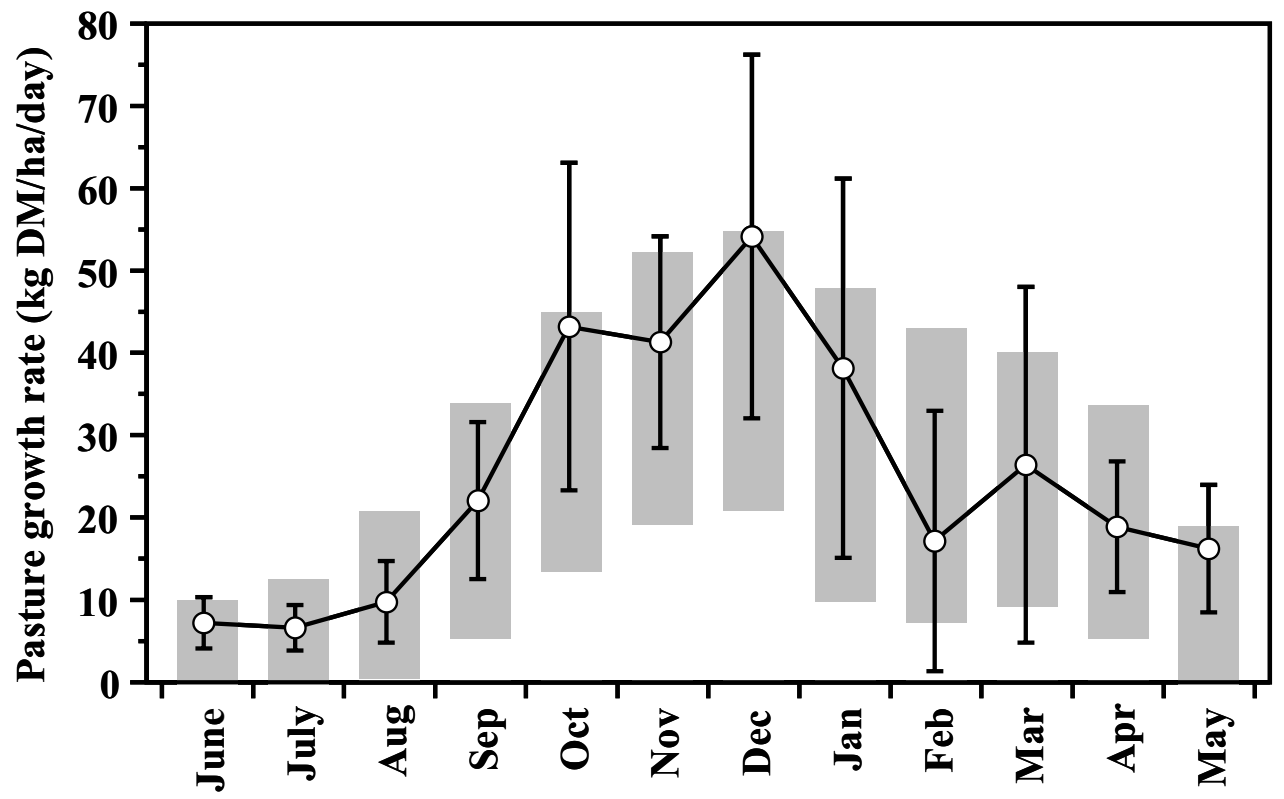

Figure 2 Mean daily nitrogen leaching (- $\bullet-)$ and nitrogen fixation (- $\mathbf{\Delta}-)$, and percentage of total nitrogen leached as ammonium ( $\square$ ) for each month of the BASE simulation over a 100 year simulation period.

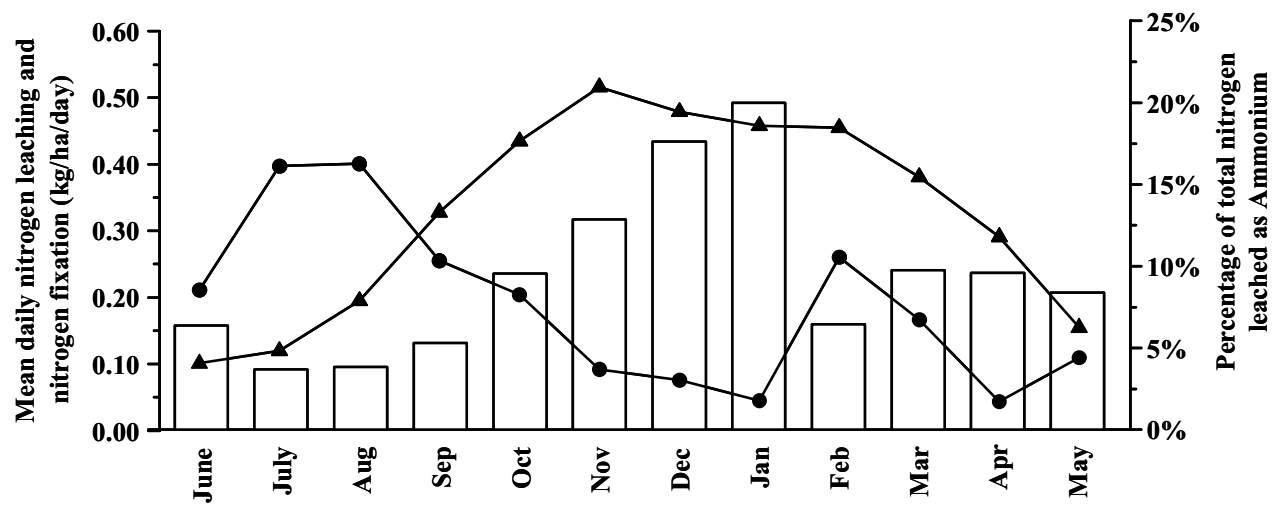



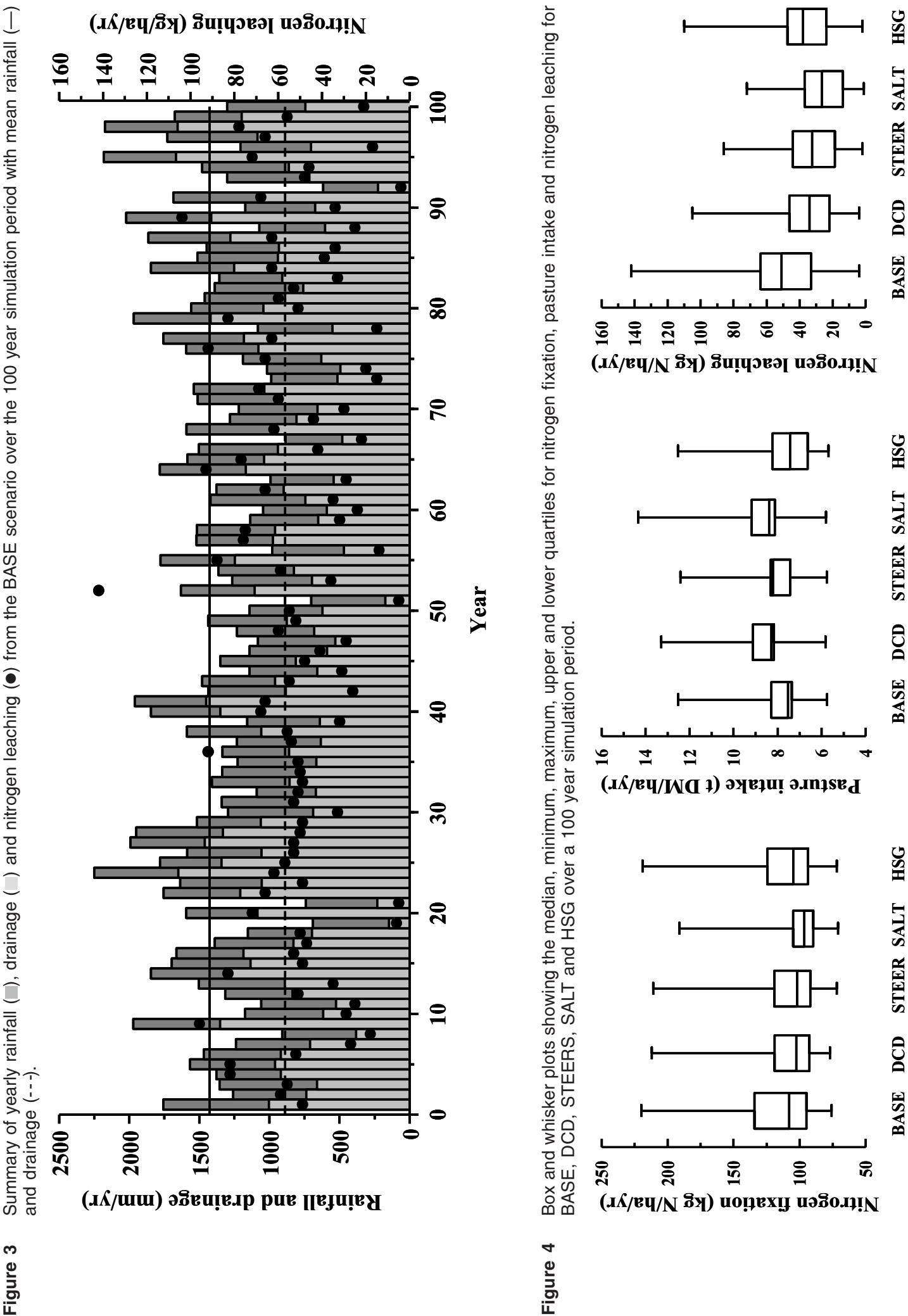

ำ 
heavy summer rainfall events. Ammonium leaching was a small, but important contributor to $\mathrm{N}$ leaching with approximately $7 \%$ of total $\mathrm{N}$ leached in this form. A higher proportion of $\mathrm{N}$ leaching as ammonium was observed in the summer months (Fig. 2), probably due to heavy summer rainfall events which leached the ammonium before it was transformed to nitrate. Nitrogen fixation was cyclical with a peak in the warmer months of November to February and a decline in the cooler months of May to August (Fig. 2), and is consistent with the findings of a farmlet study by Ledgard et al. (2001).

A high proportion $(62 \%)$ of precipitation drained through the soil profile (Fig. 3), which was expected for this porous soil with low water storage capacity. There was a significant relationship between rainfall and total $\mathrm{N}$ leaching (Pearson correlation coefficient $\mathrm{r}=0.71$; $\mathrm{P}<0.001)$, and drainage and total $\mathrm{N}$ leaching $(\mathrm{r}=0.71$; $\mathrm{P}<0.001)$ in the simulated data. Minimal $(<10 \mathrm{~kg} \mathrm{~N} / \mathrm{ha} /$ $\mathrm{yr}$ ) simulated $\mathrm{N}$ leaching was observed for years with less than $750 \mathrm{~mm}$ of rainfall and minimal drainage i.e. years 19, 21, 51 and 92 (Fig. 3).

Median N leaching for the BASE scenario was $51 \mathrm{~kg}$ $\mathrm{N} / \mathrm{ha} / \mathrm{yr}$, higher than might be expected in this region. This higher $\mathrm{N}$ leaching value is a reflection of the high simulated stocking rate (5 heifers/ha), whereas a typical value for the district might be 2.5 to 3 heifers/ha (MAF 2005). As mentioned earlier, the high stocking rate was a result of the grazing rules that ensured high utilisation of the pasture.

\section{Mitigation scenarios - effect on $\mathbf{N}$ fixation}

Simulated median N fixation (Fig. 4; $108 \mathrm{~kg} \mathrm{~N} / \mathrm{ha}$ for the BASE scenario) is within the range of 11 to $159 \mathrm{~kg} \mathrm{~N} / \mathrm{ha}$ for white clover-perennial ryegrass pastures reported by Ledgard (2001). Nitrogen fixation was significantly $(\mathrm{P}<0.05)$ reduced for all mitigation strategies, but the difference was small between HSG and BASE. The most marked reduction in $\mathrm{N}$ fixation occurred for the SALT mitigation strategy, equivalent to a $16 \mathrm{~kg} \mathrm{~N} / \mathrm{yr}$ reduction compared to the BASE. Both SALT and STEER reduced $\mathrm{N}$ fixation because urine was spread over a greater area of the paddock and led to a smaller area of the paddock being $\mathrm{N}$ deficient and conducive to more $\mathrm{N}$ fixation. The application of DCD slowed nitrification rates so that more nitrogen was retained in the soil as ammonium which is less readily leached than nitrate. Biologically, and in EcoMod, $\mathrm{N}$ fixation is lowest in areas of a paddock where soil mineral $\mathrm{N}$ content is moderate to high or clover content in pasture is low. Analyses of the simulation results identified that SALT, STEER and DCD had elevated average soil mineral $\mathrm{N}$ content and slightly lower ( 2 to $6 \%$ average reduction) clover content in the pasture than the BASE simulation.
Mitigation scenarios - effect on pasture production and intake

The mitigation strategies, DCD, STEER and SALT all significantly $(\mathrm{P}<0.05)$ increased pasture intake by the animals compared to the BASE (median of 7.5 tonnes $\mathrm{DM} / \mathrm{ha} / \mathrm{yr}$ ) with median pasture intake of $8.3,8.2$ and 8.4 tonnes $\mathrm{DM} / \mathrm{ha} / \mathrm{yr}$, respectively (Fig. 4). This increase in pasture intake was due to higher average soil mineral $\mathrm{N}$ contents as outlined above. Pasture production, and consequently intake, benefits from the use of DCD, have been reported in experimental studies (Di \& Cameron $2004 b, 2005)$. There was a small reduction in pasture intake for the HSG mitigation strategy compared to the BASE, equivalent to 0.1 tonnes $\mathrm{DM} / \mathrm{ha} / \mathrm{yr}$, which may have arisen from the greater use of $\mathrm{N}$ in animal liveweight gain, and consequently reduced output of $\mathrm{N}$ in urine that could have been used to support pasture growth.

\section{Mitigation scenarios - effect on nitrogen leaching}

Median total $\mathrm{N}$ leaching for the BASE scenario was 51 $\mathrm{kg} \mathrm{N} / \mathrm{ha} / \mathrm{yr}$. The SALT (27 kg N/ha/yr, 48\% reduction), STEER (33 kg N/ha/yr, 36\% reduction), DCD (34 kg $\mathrm{N} / \mathrm{ha} / \mathrm{yr}, 33 \%$ reduction), and HSG (38 kg N/ha/yr, $25 \%$ reduction) all resulted in significant $(\mathrm{P}<0.05)$ median reductions in $\mathrm{N}$ leaching compared to the BASE (Fig. $4)$. The greatest reduction was simulated by SALT and arose directly from urine being spread over a greater area and reducing the intensity of the nitrogen leaching hotspots. STEER was also an effective mitigation strategy as urine was spread over a greater area and more $\mathrm{N}$ was exported in animal gain. The DCD mitigation strategy slowed nitrification, and consequently less of the highly mobile nitrate was available for leaching. The assumptions for $\mathrm{HSG}$ ensured a greater proportion of $\mathrm{N}$ in faeces than urine and more $\mathrm{N}$ taken up in liveweight gain compared to the other simulations. Faecal-N needs to be incorporated into the soil and undergo microbial transformation before it is released as leachable mineral forms (i.e. nitrate and ammonium), which is not the case for urinary- $\mathrm{N}$ that is quickly converted from urea to ammonium and nitrate.

The DCD mitigation strategy reduced $\mathrm{N}$ leaching by $33 \%$, which is less than the values of 59 to $76 \%$ reported by Di and Cameron (2002). However, their results were directly from urine patches where DCD application coincided with urine application. In our simulations, DCD was applied over the whole paddock and at fixed dates which did not necessarily coincide with urine deposition. In addition, their experimental work was done on soils with a higher capacity to retain ammonium on the soil surfaces and did not consider that increased pasture growth would require an increase in stocking intensity and consequently an increase in urinary and faecal output. 


\section{Sensitivity}

The modelling of mitigation strategies was based on limited information, especially for system effects of SALT, STEER and HSG. To test the sensitivity of $\mathrm{N}$ leaching to changes in mitigation strategy assumptions, additional simulations were carried out. If SALT only resulted in a 1.5 -fold increase in the number of urinations compared to the two-fold increase described in the methods, expected N leaching was $37 \mathrm{~kg} \mathrm{~N} / \mathrm{ha} / \mathrm{yr}(27 \%$ reduction). If the area covered in urinations was the same for STEER and BASE but more $\mathrm{N}$ was still retained in liveweight gain, expected $\mathrm{N}$ leaching was $46 \mathrm{~kg} \mathrm{~N} / \mathrm{ha} / \mathrm{yr}$ (10\% reduction). Simulations for HSG assumed gains in pasture quality (digestibility and water soluble carbohydrate content), liveweight gain, and $\mathrm{N}$ partitioning will be realised in the farm system. Retaining only shifts in urine and dung partitioning and increasing pasture digestibility with no effect of HSG on animal N retention, resulted in $\mathrm{N}$ leaching of $44 \mathrm{~kg} \mathrm{~N} / \mathrm{ha} / \mathrm{yr}$ (14\% reduction). Only three applications of DCD (1 April, 1 June, and 1 August) resulted in N leaching of $43 \mathrm{~kg} \mathrm{~N} / \mathrm{ha} / \mathrm{yr}(16 \%$ reduction), potentially illustrating the need to apply DCD earlier than conventionally recommended. This prevents an accumulation of nitrate in the soil in the late summer/ early autumn, which is then susceptible to leaching with the onset of autumn rains. However, a 100-day duration of effectiveness of DCD is probably unrealistic at expected soil temperatures in the summer and early autumn (Di \& Cameron 2004a). These results illustrate $\mathrm{N}$ leaching benefits are heavily dependent on urine being spread over a greater area of the paddock for SALT and STEER, and a greater uptake of $\mathrm{N}$ in liveweight gain for HSG and STEER.

\section{Conclusion}

Each simulated mitigation strategy resulted in a significant reduction in nitrogen leaching compared to the BASE. The values for $\mathrm{N}$ leaching (along with $\mathrm{N}$ fixation and pasture production) of the simulations presented in this paper should be treated as specific for this area and soil type, with these factors expected to influence the rate of $\mathrm{N}$ leaching and the efficacy of each mitigation strategy. Results should not be taken as representative for different soils or climates and all are subject to implementation in the farm system. In certain instances, such as for HSG and to a lesser extent SALT and STEER, few data were available on which to base the simulations. Therefore, results should be treated with caution until each mitigation strategy is experimentally tested over the next 3 years (Ledgard et al. 2007). The results do, however, illustrate the use of a biophysical whole farm model, EcoMod, to test the potential effectiveness of mitigation strategies before commencing experimental studies.

\section{ACKNOWLEDGEMENTS}

This work was partially funded through FRST contract number C10X0315. We gratefully acknowledge the inputs of Keith Betteridge, Stewart Ledgard, David Wheeler, Greg Lambert and the WFSAT (www.wfsat.org) team.

\section{REFERENCES}

Anonymous 2006. Protecting Lake Taupo Strategy. Environment Waikato. 26pp Available online: www.ew.govt.nz

Baars, J.A.; Radcliffe, J.E.; Brunswick, L. 1975. Seasonal distribution of pasture production in New Zealand VI. Wairakei, pasture and lucerne production. New Zealand Journal of Experimental Agriculture 3: 253-258.

Davenport, G.M.; Boling, J.A.; Schillo, K.K. 1990. Nitrogen metabolism and somatotropin secretion in beef heifers receiving abomasal arginine infusions. Journal of Animal Science 68: 1683-1692.

Di, H.J.; Cameron, K.C. 2002. The use of a nitrification inhibitor, dicyandiamide (DCD), to decrease nitrate leaching and nitrous oxide emissions in a simulated grazed and irrigated grassland. Soil Use and Management 18: 395-403.

Di, H.J.; Cameron, K.C. 2004a. Treating grazed pasture soil with a nitrification inhibitor, eco-n ${ }^{\mathrm{TM}}$, to decrease nitrate leaching in a deep sandy soil under spray irrigation - a lysimeter study. New Zealand Journal of Agricultural Research 47: 351-361.

Di, H.J.; Cameron, K.C. 2004b. Effects of temperature and application rate of a nitrification inhibitor, dicyandiamide (DCD), on nitrification rate and microbial biomass in a grazed pasture soil. Australian Journal of Soil Research 42: 927-932.

Di, H.J.; Cameron, K.C. 2005. Reducing environmental impacts of agriculture by using a fine particle suspension nitrification inhibitor to decrease nitrate leaching from grazed pastures. Agriculture, Ecosystems andEnvironment 109: 202.

Edgar, N.B. 1999. Land use in the Taupo catchment, New Zealand. New Zealand Journal of Marine and Freshwater Research 33: 375-383.

Gibbs, M.M. 2006. Lake Taupo long term monitoring programme 2004/2005. NIWA client report: HAM2006-033. 82pp. Available online: www.ew.govt.nz

Haynes, R.J.; Williams, P.H. 1993. Nutrient cycling and soil fertility in the grazed pasture ecosystem. Advances in Agronomy 49: 119-199.

Johnson, I.R.; Chapman, D.F.; Snow, V.O.; Eckard, R.J.; Parsons, A.J.; Lambert, M.G.; Cullen, B.R. 2008. DairyMod and EcoMod: biophysical pasture simulation models for Australia and New Zealand. 
Australian Journal of Experimental Agriculture 48: in press.

Ledgard, S.F. 2001. Nitrogen cycling in low input legume-based agriculture, with emphasis on legume/ grass pastures. Plant and Soil 228: 43-59.

Ledgard, S.F.; Menneer, J.; Welten, B.; Kear, M.; Dexter, M.; Lindsey, S.; Betteridge, K.; Crush, J.R.; Pacheco, D. 2007. New nitrogen mitigation technologies for evaluation in the Lake Taupo catchment. pp. 19-24. In: Designing sustainable farms: Critical aspects of soil and water management.

Ledgard, S.F.; Sprosen, M.S.; Penno, J.W.; Rajendram, G.S. 2001. Nitrogen fixation by white clover in pastures grazed by dairy cows: Temporal variation and effects of nitrogen fertilization. Plant and Soil 229: 177-187.

MAF 2005. Sheep and Beef Monitoring Report 2004/ 2005 Report Ministry of Agriculture and Forestry.

Marini, J.C.; Van Amburgh, M.E. 2005. Partition of nitrogen excretion in urine and the feces of Holstein replacement heifers. Journal of Dairy Science 88: 1778-1784.

Merry, R.J.; Lee, M.R.F.; Davies, D.R.; Dewhurst, R.J.; Moorby, J.M.; Scollan, N.D.; Theodorou, M.K. 2006. Effects of high-sugar ryegrass silage and mixtures with red clover silage on ruminant digestion. 1. In vitro and in vivo studies of nitrogen utilization. Journal of Animal Science 84: 3049-3060.

Moorby, J.M.; Evans, R.T.; Scollan, N.D.; MacRae,
J.C.; Theodorou, M.K. 2006. Increased concentration of water-soluble carbohydrate in perennial ryegrass (Lolium perenne L.). Evaluation in dairy cows in early lactation. Grass and Forage Science 61: 52-59.

SCA 1990. Feeding standards for Australian Livestock: Ruminants. CSIRO, Australia.

Smith, L.C.; Monaghan, R.M.; Ledgard, S.; Catto, W.D. 2005. The effectiveness of different nitrification inhibitor formulations in limiting nitrate accumulation in a Southland pastoral soil. New Zealand Journal of Agricultural Research 48: 517-529.

Srikanthan, R.; Zhou, S.L. 2003. Stochastic generation of climate data. Working document 03/12. Cooperative Research Centre for Catchment Hydrology. Available online: www.toolkit.net.au/scl

Verburg, K.; Bond, W.J.; Srikanthan, R.; Frost, A.J. 2005. Predicting the impact of climatic variability on deep drainage under dryland agriculture. pp. 17161722. In: MODSIM 2005 International Congress on Modelling and Simulation. Eds. Zerger, A.;Argent, R.M. Modelling and Simulation Society of Australia and New Zealand, December 2005.

Wachendorf, C.; Taube, F.; Wachendorf, M. 2005. Nitrogen leaching from N-15 labelled cow urine and dung applied to grassland on a sandy soil. Nutrient Cycling in Agroecosystems 73: 89-100.

Wilde, R.H. Ed. 2003. Manual for National Soils Database Landcare Research, Palmerston North, New Zealand. 